\title{
BMJ
}

\section{Headache, migraine, and structural brain lesions and function: population based Epidemiology of Vascular Ageing-MRI study}

\author{
Tobias Kurth, director of research, ${ }^{1,2,3}$ Shajahal Mohamed, fellow, ${ }^{1}$ Pauline Maillard, researcher, ${ }^{4}$ Yi-Cheng Zhu, \\ neurologist, ${ }^{1,2,5,6}$ Hugues Chabriat, professor of neurology, ${ }^{5,7}$ Bernard Mazoyer, professor of radiology, 4,8,9,10 \\ Marie-Germaine Bousser, professor of neurology, ${ }^{5,7}$ Carole Dufouil, senior researcher, ${ }^{1,2}$ Christophe Tzourio, \\ senior director of research ${ }^{1,2,5}$
}

${ }^{1}$ INSERM Unit 708-

Neuroepidemiology, Paris, France

2UPMC Université Paris 06, UMR_S708, Paris, France

${ }^{3}$ Division of Preventive Medicine, Department of Medicine, Brigham and Women's Hospital, Harvard Medical School, Boston, MA, USA

${ }^{4}$ CNRS-CEA UMR 6194 Groupe d'Imagerie Neurofonctionnelle. Caen, France

${ }^{5}$ Service de Neurologie, Groupe Hospitalier Lariboisière-Fernand-

Widal, Assistance Publique

Hôpitaux de Paris, Paris, France

${ }^{6}$ Department of Neurology, Peking Union Medical College Hospital,

Beijing, China

${ }^{7}$ Université Paris Denis Diderot,

Paris, France

${ }^{8}$ Université de Caen Basse-

Normande, Caen, France

${ }^{9}$ Centre Hospitalier et

Universitaire de Caen, Caen,

France

${ }^{10}$ Institut Universitaire de France, Paris, France

Correspondence to: T Kurth, INSERM Unit 708-

Neuroepidemiology, Hôpital de la Pitié-Salpêtrière, 47 boulevard de l'Hôpital, 75651, Paris, Cedex 13,

France tobias.kurth@upmc.fr

Cite this as: BMJ 2011;342:C7357 doi:10.1136/bmj.c7357

\section{ABSTRACT}

Objective To evaluate the association of overall and specific headaches with volume of white matter hyperintensities, brain infarcts, and cognition.

Design Population based, cross sectional study.

Setting Epidemiology of Vascular Ageing study, Nantes, France.

Participants 780 participants (mean age $69,58.5 \%$ women) with detailed headache assessment.

Main outcome measures Brain scans were evaluated for volume of white matter hyperintensities (by fully automated imaging processing) and for classification of infarcts (by visual reading with a standardised assessment grid). Cognitive function was assessed by a battery of tests including the mini-mental state examination.

Results 163 (20.9\%) participants reported a history of severe headache and 116 had migraine, of whom 17 (14.7\%) reported aura symptoms. An association was found between any history of severe headache and increasing volume of white matter hyperintensities. The adjusted odds ratio of being in the highest third for total volume of white matter hyperintensities was 2.0 (95\% confidence interval 1.3 to 3.1 , P for trend 0.002 ) for participants with any history of severe headache when compared with participants without severe headache being in the lowest third. The association pattern was similar for all headache types. Migraine with aura was the only headache type strongly associated with volume of deep white matter hyperintensities (highest third odds ratio $12.4,1.6$ to $99.4, \mathrm{P}$ for trend 0.005 ) and with brain infarcts $(3.4,1.2$ to 9.3). The location of infarcts was predominantly outside the cerebellum and brain stem. Evidence was lacking for cognitive impairment for any headache type with or without brain lesions.

Conclusions In this population based study, any history of severe headache was associated with an increased volume of white matter hyperintensities. Migraine with aura was the only headache type associated with brain infarcts. Evidence that headache of any type by itself or in combination with brain lesions was associated with cognitive impairment was lacking.

\section{INTRODUCTION}

Many people in the general population have primary and often disabling headache disorders. ${ }^{1-3}$ The most common forms are migraine and tension-type headache. Migraine is a recurrent primary headache disorder that has close links to the neuronal and cerebrovascular system, and in some patients is accompanied by transient neurological symptoms, mostly of the visual field, known as migraine aura.

Headaches in general and migraine in particular have been associated with an increased risk of comorbidities. ${ }^{14}$ Evidence is accumulating that migraine with aura is a marker for increased risk of cardiovascular disease, ${ }^{5-7}$ specifically stroke. ${ }^{89}$ In addition, migraine has been associated with a variety of structural brain lesions, including clinically silent infarct-like lesions ${ }^{1011}$ in the posterior circulation territory and with white matter hyperintensities (lesions appearing in white matter on magnetic resonance imaging of the brain). White matter hyperintensities can be seen in some apparently healthy people ${ }^{12}$ and in patients with motor and cognitive dysfunctions. ${ }^{13-16}$ These lesions have been commonly interpreted as lesions of ischaemic origin, which is consistent with their association with vascular risk factors ${ }^{1718}$ and increased risk of ischaemic stroke. ${ }^{16}$

Several studies have reported an association between migraine and white matter hyperintensities. ${ }^{19-22}$ A meta-analysis indicated a fourfold increased risk for these lesions in people with migraine compared with controls. ${ }^{23}$ Many uncertainties remain, however, as some of the studies linking migraine with white matter hyperintensities had no direct migraine-free control group, ${ }^{20}$ did not include people over age $60,{ }^{222425}$ or used a case-control design. ${ }^{23}$ Furthermore, initial evidence suggests that other headache types are also associated with white matter hyperintensities, ${ }^{26}$ but most studies had no 
Table 1|Association of headache status with personal characteristics and volume of white matter hyperintensities (WMH) in Epidemiology of Vascular Ageing study $(n=780)$. Values are numbers (percentages) unless stated otherwise

\begin{tabular}{|c|c|c|c|}
\hline Variable & $\begin{array}{c}\text { No history of } \\
\text { severe headache } \\
(n=617)\end{array}$ & $\begin{array}{l}\text { Migraine } \\
\text { headache } \\
(n=116)\end{array}$ & $\begin{array}{c}\text { Non-migraine } \\
\text { headache } \\
(n=47)\end{array}$ \\
\hline Mean (SD) age (years) & $68.8(2.9)$ & $68.9(2.8)$ & $69.5(3.1)$ \\
\hline Women & $331(53.6)$ & $99(85.3)$ & $26(55.3)$ \\
\hline Mean (SD) systolic blood pressure (mm Hg) & $135.1(19.6)$ & $131.7(20.5)$ & $137.2(21.7)$ \\
\hline Mean (SD) cholesterol level (mmol/L) & $6.1(1.0)$ & $6.3(1.0)$ & $6.1(0.7)$ \\
\hline $\begin{array}{l}\text { Mean (SD) low density lipoprotein cholesterol level } \\
(\mathrm{mmol} / \mathrm{L})\end{array}$ & $3.8(0.9)$ & $4.0(0.9)$ & $3.8(0.8)$ \\
\hline Mean (SD) triglyceride level (mmol/L) & $1.3(0.6)$ & $1.3(0.6)$ & $1.4(0.7)$ \\
\hline Mean (SD) glucose level (mmol/L) & $5.5(1.1)$ & $5.3(1.2)$ & $5.5(0.7)$ \\
\hline \multicolumn{4}{|l|}{ Body mass index: } \\
\hline$<25$ & $271(44.4)$ & $48(42.5)$ & $18(39.1)$ \\
\hline $25-29.9$ & $255(41.7)$ & $55(48.7)$ & $19(41.3)$ \\
\hline$\geq 30$ & $85(13.9)$ & $10(8.8)$ & $9(19.6)$ \\
\hline Ever smoker & 277 (44.9) & $33(28.4)$ & $21(44.7)$ \\
\hline \multicolumn{4}{|l|}{ Alcohol intake (g/day): } \\
\hline 0 & $162(26.3)$ & $53(45.7)$ & $13(27.7)$ \\
\hline $1-19$ & $270(43.8)$ & $43(37.1)$ & $22(46.8)$ \\
\hline $20-39$ & $112(18.2)$ & $16(13.8)$ & $6(12.8)$ \\
\hline$\geq 40$ & 73 (11.8) & $4(3.4)$ & $6(12.8)$ \\
\hline History of hypertension & $215(34.8)$ & $51(44.0)$ & $18(38.3)$ \\
\hline Family history of severe headache & $154(25.0)$ & $49(42.2)$ & $21(44.7)$ \\
\hline History of cardiovascular disease & $44(7.1)$ & $7(6.0)$ & $5(10.6)$ \\
\hline Median (interquartile range) total WMH volume $\left(\mathrm{cm}^{2}\right)$ & $3.3(2.2-5.0)$ & $3.5(2.4-6.0)$ & $3.8(2.9-6.8)$ \\
\hline Median (interquartile range) deep WMH volume $\left(\mathrm{cm}^{2}\right)$ & $0.8(0.5-1.4)$ & $1.0(0.6-1.6)$ & $1.1(0.7-1.6)$ \\
\hline $\begin{array}{l}\text { Median (interquartile range) periventricular WMH volume } \\
\left(\mathrm{cm}^{2}\right)\end{array}$ & $2.3(1.5-3.8)$ & $2.7(1.4-4.6)$ & $2.6(1.9-5.0)$ \\
\hline
\end{tabular}

Percentages may not add up to $100 \%$ owing to rounding or missing values.

information on non-migraine headache. In addition, it remains unclear whether structural brain lesions among people with headache are associated with impaired cognitive function. We evaluated the association of overall and specific headache types with volume of white matter hyperintensities and infarct lesions as well as with cognitive performance in the population based Epidemiology of Vascular Ageing study.

\section{METHODS}

The Epidemiology of Vascular Ageing study is a longitudinal study that recruited men and women born between 1922 and 1932 from the electoral rolls of the city of Nantes, France, without specific exclusion criteria. ${ }^{27}$ During the baseline visit (1991-3), 1389 participants were enrolled. In a face to face interview at the examination centre, standardised questionnaires were used to ascertain information about demographics and medical history as well as personal characteristics and habits, such as cigarette and alcohol consumption. Trained staff measured height, weight, and blood pressure and took fasting blood samples following standardised procedures. ${ }^{28}$ Written informed consent was obtained from all participants.

\section{Headache assessment}

Information on headache was ascertained in a two step approach among 1188 people who participated in the second follow-up visit, four years after the baseline visit. Firstly, during a face to face interview, trained staff asked participants standardised questions about lifetime history of severe headaches and headache features. Interviewers were specially trained to administer the questionnaire and to ask the questions. Interviewers were instructed to insist on the screening question about headache history to avoid missing participants with a potential for recurrent severe headaches during their lifetime and particularly during their young adulthood. ${ }^{29}$ Secondly, participants who reported a history of severe headaches were asked to take part in a telephone interview with a neurologist specialised in headaches using a structured questionnaire. $^{30}$ This questionnaire has been shown to have good inter-rater agreement $(\kappa=0.83)^{31}$ and included information on duration of headaches; lifetime frequency of episodes; intensity of the pain; characteristics and location of the pain; association of the pain with physical activity; associated features, such as sensitivity to sound and light as well as nausea; and information about aura features. A total of 242 participants were eligible for the interview. Of those, four died before the interview, four were unreachable or opted not to participate, and one had severe hearing impairment, leaving 233 participants who were interviewed. Information on detailed lifetime history of headache, specific migraine features, and aura symptoms were ascertained during the interview.

The collected information allowed classification of headache based on the second revision of the International Classification of Headache Disorders. ${ }^{32}$ We classified patients who reported a history of severe headache as having migraine if the headache and associated features fulfilled all or all but one of the classification criteria for migraine without aura. ${ }^{32}$ In addition, we classified patients with migraine according to migraine aura status. Participants with a history of headache not fulfilling the criteria for migraine were classified as having non-migraine headache, a group of patients likely to have tension-type headache because other headache types are rare in the general population. ${ }^{33}$

\section{Magnetic resonance imaging examination}

At the second follow-up visit (at the same time as ascertainment of headache), 845 participants ( $88 \%$ participation rate) underwent cerebral magnetic resonance imaging, as described in detail elsewhere. ${ }^{17}$ Participants had similar baseline characteristics to those who did not participate. ${ }^{17}$ The distribution of headache status was also similar between the two groups $(\mathrm{P}=0.38)$.

Brain scanning was carried out with a 1.0 tesla scanner (Magnetom Expert; Siemens, Erlangen, Germany), with the orbitomeatal line as reference. Firstly, we acquired a high resolution T1 weighted brain volume using a three dimensional inversion 
Table 2|Association between headache history and volume of white matter hyperintensities (WMH) in Epidemiology of Vascular Ageing study ( $\mathrm{n}=780$ )

\begin{tabular}{|c|c|c|c|c|c|c|c|}
\hline \multirow[b]{2}{*}{$\begin{array}{l}\text { WMH volume by } \\
\text { thirds }\end{array}$} & \multirow{2}{*}{ 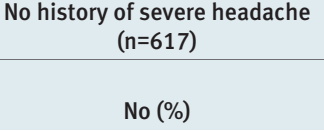 } & \multicolumn{3}{|c|}{$\begin{array}{l}\text { Migraine headache } \\
\quad(n=116)\end{array}$} & \multicolumn{3}{|c|}{$\begin{array}{l}\text { Non-migraine headache } \\
\qquad(\mathrm{n}=47)\end{array}$} \\
\hline & & No (\%) & $\begin{array}{l}\text { Age adjusted odds } \\
\text { ratio }(95 \% \mathrm{Cl})\end{array}$ & $\begin{array}{l}\text { Multiple adjusted* } \\
\text { odds ratio }(95 \% \mathrm{Cl})\end{array}$ & No (\%) & $\begin{array}{l}\text { Age adjusted odds } \\
\text { ratio }(95 \% \mathrm{Cl})\end{array}$ & $\begin{array}{l}\text { Multiple adjusted* } \\
\text { odds ratio }(95 \% \mathrm{Cl})\end{array}$ \\
\hline \multicolumn{8}{|l|}{ Total: } \\
\hline Lowest third & 215 (34.8) & $35(30.2)$ & 1.0 & 1.0 & $10(21.3)$ & 1.0 & 1.0 \\
\hline Middle third & $211(34.2)$ & $34(29.3)$ & 1.0 (0.6 to 1.6$)$ & 1.0 (0.6 to 1.6$)$ & 15 (31.9) & 1.5 (0.7 to 3.5$)$ & 1.6 (0.7 to 3.6$)$ \\
\hline Highest third & $191(31.0)$ & $47(40.5)$ & 1.5 (0.9 to 2.4 ) & 1.8 (1.0 to 2.9 ) & $22(46.8)$ & 2.4 (1.1 to 5.2$)$ & 2.7 (1.2 to 5.9$)$ \\
\hline $\mathrm{P}$ for trend $\dagger$ & - & - & 0.07 & 0.03 & - & 0.03 & 0.01 \\
\hline \multicolumn{8}{|l|}{ Deep: } \\
\hline Lowest third & $213(34.5)$ & $34(29.3)$ & 1.0 & 1.0 & $13(27.7)$ & 1.0 & 1.0 \\
\hline Middle third & $214(34.7)$ & $34(29.3)$ & 1.0 (0.6 to 1.7$)$ & 1.1 (0.7 to 2.0 ) & $12(25.5)$ & 1.0 (0.4 to 2.2$)$ & 1.0 (0.4 to 2.2$)$ \\
\hline Highest third & $190(30.8)$ & $48(41.4)$ & 1.6 (1.0 to 2.6$)$ & 1.9 (1.1 to 3.2$)$ & $22(46.8)$ & 2.0 (1.0 to 4.0$)$ & 2.1 (1.0 to 4.4$)$ \\
\hline$P$ for trend $†$ & - & - & 0.04 & 0.01 & - & 0.04 & 0.03 \\
\hline \multicolumn{8}{|l|}{ Periventricular: } \\
\hline Lowest third & $215(34.8)$ & $36(31.0)$ & 1.0 & 1.0 & 9 (19.1) & 1.0 & 1.0 \\
\hline Middle third & $210(34.0)$ & $33(28.4)$ & 0.9 (0.6 to 1.6$)$ & 0.9 (0.5 to 1.5$)$ & $17(36.2)$ & 1.9 (0.8 to 4.3$)$ & $2.0(0.9$ to 4.7$)$ \\
\hline Highest third & $192(31.1)$ & $47(40.5)$ & 1.5 (0.9 to 2.4$)$ & 1.6 (1.0 to 2.7$)$ & $21(44.7)$ & 2.5 (1.1 to 5.6$)$ & $2.9(1.3$ to 6.5$)$ \\
\hline$P$ for trend $†$ & - & - & 0.09 & 0.04 & - & 0.03 & 0.01 \\
\hline
\end{tabular}

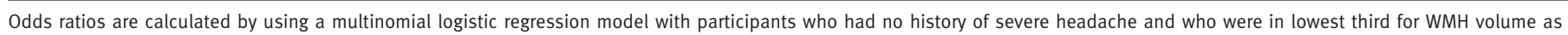
reference group. WMH volume was standardised to total white matter volume. Percentages may not add up to $100 \%$ owing to rounding.

*Adjusted for age, sex, history of hypertension, smoking, body mass index, total cholesterol level, alcohol consumption, and family history of severe headache.

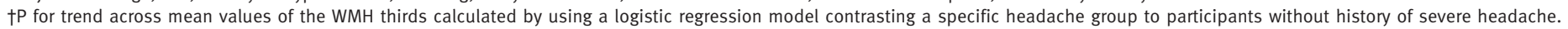

recovery spoiled gradient echo sequence (repetition time $97 \mathrm{~ms}$, echo time $4 \mathrm{~ms}$, inversion time $300 \mathrm{~ms}$, sagittal acquisition). The volume matrix was $128 \times 256 \times 256$, slice thickness $1.4 \mathrm{~mm}$, and pixel size $0.9 \times 0.9 \mathrm{~mm}^{2}$. We obtained T2 weighted and proton density weighted brain images using a two dimensional axial turbo spin echo sequence (repetition time 3500 $\mathrm{ms}$, first echo time $15 \mathrm{~ms}$, second echo time $85 \mathrm{~ms}$ ) with 26 slices (each $5 \mathrm{~mm}$ thick). The acquisition matrix was $256 \times 256$ over a $23 \mathrm{~cm}$ transversal field of view and the pixel size was $0.9 \times 0.9 \mathrm{~mm}^{2}$.

\section{Image processing and categorisation of white matter hyperintensities}

We analysed brain scans using previously validated automated imaging processing. ${ }^{34}$ Briefly, we used a three step process: preprocessing, including registration, removal of non-brain tissue, and correction for bias field; detection of white matter hyperintensities on $\mathrm{T} 2$ weighted images, including removal of false positives; and post-processing, including the generation of probability maps for white matter hyperintensities and details. For each detected lesion we computed the localisation and volume. When the distance of the detected white matter hyperintensities to the ventricular system was less than $10 \mathrm{~mm}$, we labelled the location of the lesions as periventricular, otherwise we labelled the lesions as deep white matter hyperintensities. The algorithm correlated well with a semiquantitative visual rating carried out by a neuroradiologist (quadratic trend with Scheltens scale $\mathrm{P}<0.001) .{ }^{34}$

We $\log$ transformed the measures for volume of white matter hyperintensities as they were not normally distributed. Next, we standardised the volume of white matter hyperintensities to the total volume of white matter. Standardisation with total intracranial volume yielded similar results. Finally, we a priori categorised all measures for volume of white matter hyperintensities into tertiles to allow for non-linear patterns of association.

\section{Assessment of infarct lesions}

One neurologist with training in neuroradiology (YCZ), who was blinded to the headache status and any other clinical data of participants, used a standardised assessment grid to visually review all the brain scans. The characteristics of lesions were visualised simultaneously in axial, coronal, and sagittal planes. A brain infarct was defined as focal lesions of $3 \mathrm{~mm}$ or more with the same signal characteristics as cerebrospinal fluid on both $\mathrm{T} 1$ and $\mathrm{T} 2$ weighted sequences, and these were discriminated from dilated vascular space (Virchow-Robin space) according to their shapes and locations. We applied this definition to all lesions irrespective of location. An endpoint committee (YCZ, $\mathrm{HC}, \mathrm{CT}$, and TK) reviewed and classified doubtful lesions after consensus. For this analysis, we distinguished between infarcts in the cerebellum or brain stem and in other locations.

\section{Assessment of cognitive function}

The Epidemiology of Vascular Ageing study collected extensive data on cognitive performance, ${ }^{27}$ using the mini-mental state examination, Wechsler adult intelligence scale-revised, trail making test part A and B, Rey 15 item memory test, Raven progressive matrices, Benton visual retention test, Benton facial recognition 
Table 3 |Association between headache and volume of WMH volume in Epidemiology of Vascular Ageing study $(\mathrm{n}=780)$

\begin{tabular}{|c|c|c|c|c|c|c|c|}
\hline \multirow[b]{2}{*}{$\begin{array}{l}\text { WMH volume by } \\
\text { third }\end{array}$} & \multirow{2}{*}{ 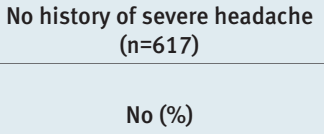 } & \multicolumn{3}{|c|}{$\begin{array}{l}\text { Migraine with aura } \\
\qquad(n=17)\end{array}$} & \multicolumn{3}{|c|}{$\begin{array}{l}\text { Migraine without aura } \\
\qquad(n=99)\end{array}$} \\
\hline & & No (\%) & $\begin{array}{l}\text { Age adjusted odds } \\
\text { ratio }(95 \% \mathrm{Cl})\end{array}$ & $\begin{array}{l}\text { Multiple adjusted* } \\
\text { odds ratio }(95 \% \mathrm{Cl})\end{array}$ & No (\%) & $\begin{array}{l}\text { Age adjusted odds } \\
\text { ratio }(95 \% \mathrm{Cl})\end{array}$ & $\begin{array}{l}\text { Multiple adjusted* } \\
\text { odds ratio }(95 \% \mathrm{Cl})\end{array}$ \\
\hline \multicolumn{8}{|l|}{ Total $(n=260)$ : } \\
\hline Lowest third & $215(34.8)$ & $4(23.5)$ & 1.0 & 1.0 & $31(31.3)$ & 1.0 & 1.0 \\
\hline Middle third & $211(34.2)$ & $5(29.4)$ & 1.3 (0.3 to 4.8$)$ & $1.2(0.3$ to 4.6$)$ & $29(29.3)$ & $1.0(0.6$ to 1.6$)$ & 0.9 (0.5 to 1.6$)$ \\
\hline Highest third & $191(31.0)$ & $8(47.1)$ & 2.3 (0.7 to 7.8$)$ & 2.7 (0.8 to 9.3) & $39(39.4)$ & $1.4(0.8$ to 2.4$)$ & 1.6 (0.9 to 2.8$)$ \\
\hline P for trend $†$ & - & - & 0.16 & 0.07 & - & 0.15 & 0.08 \\
\hline \multicolumn{8}{|l|}{ Deep $(n=260)$ : } \\
\hline Lowest third & $213(34.5)$ & $1(5.9)$ & 1.0 & 1.0 & $33(33.3)$ & 1.0 & 1.0 \\
\hline Middle third & $214(34.7)$ & $6(35.3)$ & $6.0(0.7$ to 50.0$)$ & $6.2(0.7$ to 52.5$)$ & $28(28.3)$ & 0.8 (0.5 to 1.5$)$ & $1.0(0.6$ to 1.7$)$ \\
\hline Highest third & $190(30.8)$ & $10(58.8)$ & $11.2(1.4$ to 88.3$)$ & $12.4(1.6$ to 99.4$)$ & $38(38.4)$ & $1.3(0.8$ to 2.1$)$ & 1.6 (0.9 to 2.7$)$ \\
\hline$P$ for trend $†$ & - & - & 0.008 & 0.005 & - & 0.24 & 0.11 \\
\hline \multicolumn{8}{|l|}{$\begin{array}{l}\text { Periventricular } \\
(n=260):\end{array}$} \\
\hline Lowest third & $215(34.8)$ & $5(29.4)$ & 1.0 & 1.0 & $31(31.3)$ & 1.0 & 1.0 \\
\hline Middle third & $210(34.0)$ & $4(23.5)$ & $0.8(0.2$ to 3.1$)$ & $0.8(0.2$ to 3.1$)$ & $29(29.3)$ & $1.0(0.6$ to 1.6$)$ & 0.9 (0.5 to 1.6$)$ \\
\hline Highest third & $192(31.1)$ & $8(47.1)$ & 1.8 (0.6 to 5.7$)$ & 2.1 (0.7 to 6.8) & $39(39.4)$ & $1.4(0.8$ to 2.3$)$ & 1.6 (0.9 to 2.7$)$ \\
\hline P for trend $†$ & - & - & 0.24 & 0.12 & - & 0.16 & 0.10 \\
\hline
\end{tabular}

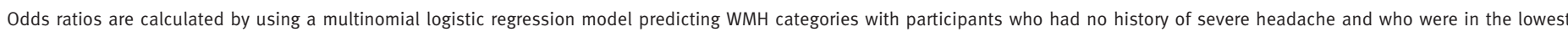
third for WMH volume as reference group. WMH volume was standardised to total white matter volume. Percentages may not add up to $100 \%$ owing to rounding.

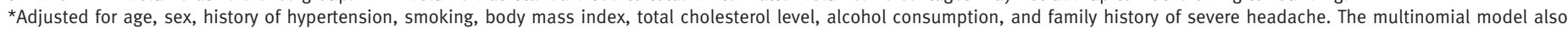
includes participants with non-migraine headache $(n=47)$; see table 2 for detailed numbers.

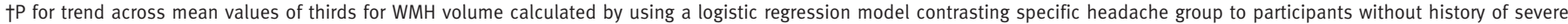
headache.

test, and word fluency test. All tests were done by trained psychologists and we used data ascertained at the second follow-up visit. As all tests gave a similar association pattern and the mini-mental state examination is the most widely used test of global cognitive function, we report findings from the mini-mental state examination only. ${ }^{35}$ This test includes simple questions in several domains, such as time and location, repeating lists of words, arithmetic (for example, serial sevens), language use and comprehension, and basic motor skills.

\section{Statistical analysis}

Of the 845 participants with brain scans, we excluded 20 for technical reasons, eight because of cerebral anomalies, 28 with image contrast precluding the application of the algorithm for measuring volume of white matter hyperintensities, and nine with missing information on headache history, leaving 780 participants for this study. Eleven participants had missing information for the mini-mental state examination and were excluded from that part of the analysis.

We compared the means of continuous characteristics and frequency of categorical characteristics of participants according to their headache status. We used multinominal logistic regression models to calculate odds ratios and 95\% confidence intervals of the association between headache status and thirds for volume of white matter hyperintensities using participants who did not report a history of severe headache and who were in the lowest third for volume of white matter hyperintensities as the reference group. Multinomial logistic regression is an extension of binary logistic regression that allows the outcome variable to have more than two categories. Calculated odds ratios have two reference categories, one for the exposure (headache status) and one for the outcome (thirds for volume of white matter hyperintensities) categories.

We run age adjusted and multivariable adjusted models for total and localised white matter hyperintensities. The multivariable models controlled for age (continuous), sex, history of hypertension (yes, no), smoking (ever, never), body mass index $(<25,25$ to $29, \geq 30$ weight $(\mathrm{kg}) /\left(\right.$ height $\left.(\mathrm{m})^{2}\right)$, alcohol consumption (0, 1-19, 20-39, $\geq 40 \mathrm{~g} /$ day), serum total cholesterol level (continuous), and family history of severe headache (yes, no). Results remained essentially unchanged when the models were additionally controlled for a history of diabetes, systolic blood pressure, and history of vascular disease. We calculated $\mathrm{P}$ for trend across mean values of the categories for volume third by using a logistic regression model contrasting a specific headache type to participants without a history of headache.

Because the volumes of localised and total white matter hyperintensities are correlated, we used the residual method ${ }^{36}$ to evaluate the association between headache types and volume of localised white matter hyperintensities - that is, deep or periventricularabove and beyond the association with the total volume.

In exploratory analyses we stratified the association between headache status and volume of white matter hyperintensities (highest third $v$ lowest two thirds) by age $(<70, \geq 70$ years), sex, history of hypertension, 
Table $4 \mid$ Frequency of infarcts according to location and headache status in Epidemiology of Vascular Ageing study ( $n=780)$. Values are numbers (percentages)

\begin{tabular}{|c|c|c|c|c|c|c|}
\hline Location & $\begin{array}{c}\text { No of participants } \\
\text { affected }\end{array}$ & $\begin{array}{c}\text { No history of } \\
\text { severe headache } \\
(n=617)\end{array}$ & $\begin{array}{c}\text { Non-migraine } \\
\text { headache }(n=47)\end{array}$ & $\begin{array}{l}\text { Any migraine } \\
\quad(n=116)\end{array}$ & $\begin{array}{l}\text { Migraine with } \\
\text { aura }(n=17)\end{array}$ & $\begin{array}{l}\text { Migraine without } \\
\text { aura }(n=99)\end{array}$ \\
\hline Cortex & 11 & $9(1.5)$ & $1(2.1)$ & $1(0.9)$ & $0(0)$ & $1(1.0)$ \\
\hline Subcortex & 42 & $34(5.5)$ & $1(2.1)$ & $7(6.0)$ & $2(11.8)$ & $5(5.1)$ \\
\hline Nucleus lentiformis & 32 & $26(4.2)$ & $0(0)$ & $6(5.2)$ & $2(11.8)$ & $4(4.0)$ \\
\hline Nucleus caudatus & 20 & $17(2.8)$ & $1(2.1)$ & $2(1.7)$ & $1(5.9)$ & $1(1.0)$ \\
\hline Thalamus & 14 & $11(1.8)$ & $1(2.1)$ & $2(1.7)$ & $2(11.8)$ & $0(0)$ \\
\hline Internal capsule & 5 & $5(0.8)$ & $0(0)$ & $0(0)$ & $0(0)$ & $0(0)$ \\
\hline Brain stem & 8 & $7(1.1)$ & $0(0)$ & $1(0.9)$ & $0(0)$ & $1(1.0)$ \\
\hline Cerebellum & 19 & $17(2.8)$ & $0(0)$ & $2(1.7)$ & $1(5.9)$ & $1(1.0)$ \\
\hline Multiple infarcts & 28 & $23(3.7)$ & $1(2.1)$ & $4(3.4)$ & $2(11.8)$ & $2(2.0)$ \\
\hline
\end{tabular}

smoking (ever $v$ never), family history of severe headache, and history of cardiovascular disease, adjusting for age. We further evaluated whether the association between migraine and volume of white matter hyperintensities was modified by full classification criteria for migraine. ${ }^{32}$ We evaluated statistically significant effect modification by including interaction terms in the models.

We used an age adjusted logistic regression model to calculate odds ratio of infarcts according to headache status. We did not aim to adjust for additional potential confounders because of the relatively low number of infarcts in subgroups. When we ran such models, however, the effect estimates were not meaningfully different.

We used general linear models, adjusting for age, sex, and education, to evaluate the association of the mini-mental state examination according to headache type with and without structural brain lesions. Evaluation of the results for performance of other cognitive tests showed a similar association pattern (data not shown). All analyses were done using SAS version 9.1; $\mathrm{P}$ values were two tailed and we considered $\mathrm{P}<0.05$ to be statistically significant.

\section{RESULTS}

Of the 780 participants with complete information on headaches and brain scans, $163(20.9 \%)$ reported a history of severe headache. Of the 116 participants with migraine, $17(14.7 \%)$ reported aura symptoms. Table 1 summarises the association between personal characteristics and headache status. Participants with migraine were more likely to be female, to be never smokers, and to be less likely to drink alcohol when compared with participants who did not report a history of headaches. Both migraine and non-migraine headache groups were more likely to have a positive family history of severe headaches.

When the association between any history of headaches and volume of white matter hyperintensities was evaluated, stronger associations were found with increasing volume. For participants with any history of severe headache, the multivariable adjusted odds ratio of being in the highest volume third for total white matter hyperintensities was 2.0 (95\% confidence interval 1.3 to 3.1 , P for trend 0.002 ) compared with participants who were in the lowest third and who did not have a headache history. Similar associations were found for volume of deep white matter hyperintensities (2.0, 1.3 to 3.1, $\mathrm{P}$ for trend 0.002$)$ and for volume of periventricular white matter hyperintensities $(1.9,1.2$ to 3.0, $\mathrm{P}$ for trend 0.004 ).

When a distinction was made between migraine and non-migraine headache, the risk increased for both headache types, with higher estimates for the group with non-migraine headaches (table 2).

Table 3 summarises the association between migraine and volume of white matter hyperintensities by migraine aura status. Although the association pattern of migraine without aura and volume of white matter hyperintensities was of the same magnitude as those for overall headache, stronger associations were found between migraine with aura and lesions located in the deep white matter $(12.4,1.6$ to 99.4 for the highest third, $\mathrm{P}$ for trend 0.005$)$. This association remained significant when the correlation between volume of localised and total white matter hyperintensities was taken into account (5.8, 1.2 to 27.8 , $\mathrm{P}$ for trend 0.02$)$.

We evaluated whether the association between headache status and increased total volume of white matter hyperintensities (highest third $v$ lowest two thirds) was modified by age, sex, history of hypertension, smoking status, family history of severe headache, history of cardiovascular disease, or classification criteria for headache status. A significant interaction of the association between non-migraine headache and total volume of white matter hyperintensities was found by age only (P for interaction 0.03 ), indicating a significant association among participants aged 70 and older $(3.4,1.5$ to 8.0$)$.

A total of $110(14.1 \%)$ participants had at least one brain infarct and 28 had more than one (table 4$)$. Compared with participants without a history of severe headache, those with a history of overall migraine or non-migraine headache had no increased risk of a brain infarct. Only participants who had migraine with aura had over a threefold increased risk (3.4, 1.2 to 9.3). Furthermore, there was a suggestion that participants who had migraine with aura were at increased 
Table 5| Mini-mental state examination (MMSE) scores according to headache status and structural brain lesions in Epidemiology of Vascular Ageing study $(n=769)$ adjusted for age, sex, and education

\begin{tabular}{|c|c|c|c|c|c|c|}
\hline \multirow[b]{2}{*}{ WMH volume by thirds } & \multicolumn{2}{|c|}{$\begin{array}{l}\text { No history of severe headache } \\
\qquad(n=608)\end{array}$} & \multicolumn{2}{|c|}{ Migraine headache $(n=116)$} & \multicolumn{2}{|c|}{ Non-migraine headache $(n=45)$} \\
\hline & No (\%) & Mean (SE) MMSE & No (\%) & Mean (SE) MMSE & No (\%) & Mean (SE) MMSE \\
\hline \multicolumn{7}{|l|}{ Total: } \\
\hline Lowest third $(n=259)$ & $214(35.2)$ & $27.5(0.1)$ & $35(30.2)$ & $27.6(0.4)$ & $10(22.2)$ & $28.6(0.5)$ \\
\hline Middle third $(n=258)$ & $210(34.5)$ & $27.6(0.1)$ & $34(29.3)$ & $27.5(0.4)$ & $14(31.1)$ & $27.8(0.5)$ \\
\hline Highest third $(n=252)$ & $184(30.3)$ & $27.5(0.2)$ & $47(40.5)$ & $27.9(0.3)$ & $21(46.7)$ & $27.8(0.4)$ \\
\hline$P$ value & & 0.68 & & 0.71 & & 0.42 \\
\hline \multicolumn{7}{|l|}{ Deep: } \\
\hline Lowest third $(n=259)$ & $212(34.9)$ & $27.6(0.1)$ & $34(29.3)$ & $27.2(0.4)$ & $13(28.9)$ & $27.9(0.5)$ \\
\hline Middle third $(n=258)$ & $212(34.9)$ & $27.5(0.1)$ & $34(29.3)$ & $27.7(0.4)$ & $12(26.7)$ & $28.4(0.6)$ \\
\hline Highest third $(n=252)$ & $184(30.3)$ & $27.5(0.2)$ & $48(41.4)$ & $28.1(0.3)$ & $20(44.4)$ & $27.8(0.4)$ \\
\hline$P$ value & & 0.86 & & 0.19 & & 0.63 \\
\hline \multicolumn{7}{|l|}{ Periventricular: } \\
\hline Lowest third $(n=259)$ & $213(35.0)$ & $27.4(0.1)$ & $36(31.0)$ & $27.7(0.4)$ & $9(20.0)$ & $28.7(0.7)$ \\
\hline Middle third $(n=257)$ & $208(34.2)$ & $27.7(0.1)$ & $33(28.4)$ & $27.6(0.4)$ & $16(35.6)$ & $27.9(0.4)$ \\
\hline Highest third $(n=254)$ & $187(30.8)$ & $27.5(0.2)$ & $47(40.5)$ & $27.8(0.3)$ & $20(44.4)$ & $27.7(0.4)$ \\
\hline$P$ value & & 0.44 & & 0.94 & & 0.53 \\
\hline No infarction $(n=660)$ & $519(85.4)$ & $27.6(0.1)$ & $99(85.3)$ & $27.7(0.2)$ & $42(93.3)$ & $28.0(0.2)$ \\
\hline Any infarct lesion $(n=109)$ & 89 (14.6) & $27.2(0.2)$ & $17(14.7)$ & $27.9(0.5)$ & $3(6.7)$ & $27.6(1.0)$ \\
\hline$P$ value & & 0.17 & & 0.69 & & 0.72 \\
\hline Overall mean (SE) & & $27.5(0.1)$ & & $27.7(0.2)$ & & $28.1(0.3)$ \\
\hline
\end{tabular}

risk of multiple infarcts (3.7, 0.8 to 17.3$)$. Most infarcts were located outside of the cerebellum or brain stem (3.5, 1.2 to 10.2$)$.

Mini-mental state examination scores were available for a total of 769 participants, with scores ranging from 17 to 30 (mean 27.6 (SD) 2.1). Mean scores adjusted for age, sex, and education did not differ according to headache status $(\mathrm{P}=0.17)$. Results were similar when median values were compared (data not shown). The mean score was highest among participants who had migraine with aura (score 28.4). Evidence was lacking that cognitive function was impaired for participants with migraine or non-migraine headache according to structural brain lesions (table 5). Evidence was also lacking for cognitive impairment according to brain lesions in participants who had migraine with aura (data not shown).

\section{DISCUSSION}

In this large, cross sectional population based sample of older participants (mean age 69) we found that any lifetime history of severe headaches was associated with an increased risk of higher volumes of total, deep, and periventricular white matter hyperintensity. The pattern of association was similar for both migraine and nonmigraine headache types. Conversely, evidence was lacking that a history of severe headache in general was associated with brain infarcts, although such an association was found for the small group of participants who had migraine with aura. Finally, we found no evidence that overall headache or specific headache type by itself or in combination with structural brain lesions results in cognitive impairment.

\section{Strengths and weaknesses of the study}

Our study has several strengths, including the large number of participants drawn independently according to headache status from the general population, classification of headache status through a structured and standardised telephone interview carried out by neurologists who were specialised in headache disorders, utilisation of validated automated image processing $^{34}$ to classify volume of white matter hyperintensities, and the large amount of available information allowing for the control of potential confounding factors.

Several limitations should also be considered. Firstly, despite the large study size, the subgroups comprised a relatively small number of participants, which should particularly caution the interpretation of the results for migraine with aura $(n=17)$. Secondly, our study was cross sectional, which does not necessarily allow evaluation of the direction of association. However, most of the participants with headache reported first onset in young age, when structural brain lesions are rare. Thirdly, not all participants took part in the brain imaging substudy, which could potentially result in selection bias. However, the measured characteristics, ${ }^{17}$ and particularly the distribution of headache history, did not differ among participants and non-participants $(\mathrm{P}=0.38)$. Fourthly, although headache status was ascertained by a detailed interview with a headache specialist, information on headaches may not have been recalled adequately in this older population. As white matter hyperintensities have been associated with increased risk of dementia, ${ }^{14} \mathrm{a}$ differential bias is possible. Such a bias would, 
however, have underestimated the association between headache status and white matter hyperintensities. Furthermore, our initial screening question for headache asked for "severe" headache to identify patients with considerable headache burden, which may not allow all people who have headaches to be captured. However, such a screening tool is often used in population based headache research. ${ }^{2237}$ Fifthly, despite adjustment for a large number of potential confounders, residual and unmeasurable confounding is possible because our study was observational. Sixthly, our data were collected some time ago. Although the associations between migraine and structural brain lesions or function are unlikely to have changed, newer imaging techniques are available, which may lead to more precise detection of lesions. Lastly, the participants were of higher socioeconomic status and somewhat healthier than their peer group, ${ }^{27}$ which may limit generalisability to other populations.

\section{Comparisons with previous studies}

Our findings extend our knowledge of the association between headache and white matter hyperintensities to non-migraine headache, which is likely to be tensiontype headache, and to older people. Previous population based studies could only evaluate the association between migraine and white matter hyperintensities, showing increased risk. ${ }^{203839}$ In a meta-analysis of case-control studies, migraine was associated with a fourfold increased risk (odds ratio 3.9, 95\% confidence interval 2.26 to 6.72 ) of white matter abnormalities. ${ }^{23}$ For tension-type headache, our data confirm results from a previous small case-control study of 63 patients with chronic primary headache and 54 controls free of headache. ${ }^{26}$ This imaging study found that the prevalence of white matter abnormalities was similar for tension-type and migraine headaches $(32.1 \%$ and $34.3 \%)$ and both were increased compared with controls (7.4\%).

Our results of a strong association between migraine with aura and deep white matter hyperintensities extend the findings of the Cerebral Abnormalities in Migraine, an Epidemiological Risk Analysis (CAMERA) study. ${ }^{22}$ In this population based sample of men and women aged 20 to 60 years from the Netherlands, overall migraine was associated with an increased load of deep white matter hyperintensities among women but did not differ according to migraine aura status. The association was stronger with higher frequency of migraines, information that was not available in our study.

The CAMERA study further showed an association between migraine with aura and infarct-like lesions mainly located in the cerebellum and brain stem (odds ratio 13.7, 95\% confidence interval 1.7 to 112). ${ }^{1022}$ This finding is supported by a population based study from Iceland, which found that women with migraine in mid-life had an increased risk of cerebellar infarct-like lesions in later life. ${ }^{11}$ Although our data also support an association between migraine with aura and brain infarcts, most of these lesions were located outside the cerebellum or brain stem.

Our data do not indicate an association between overall or specific headache types and impaired cognitive function regardless of the presence of structural brain lesions. While data suggest an association between white matter hyperintensities and cognitive impairment, ${ }^{14}$ recent findings do not support an association between cognitive impairment and migraine in older people. ${ }^{40}$

\section{Potential biological mechanisms}

The mechanisms linking headache in general with white matter hyperintensities are unclear. White matter hyperintensities are believed to consist of gliosis and local loss of myelin resulting from microvascular damage. In patients with migraine, a haemodynamic ischaemic process ${ }^{41}$ and mitochondrial dysfunction ${ }^{42}$ have been hypothesised, but neuropathological investigations are lacking. ${ }^{43}$ Rarely, white matter hyperintensities among patients who have migraine with aura can be related to a genetically determined small vessel disease. $^{44}$

A potential explanation for the association between migraine with aura and brain infarcts involves links between migraine and the endovascular system, ${ }^{4546}$ shared genetic or vascular risk factors, ${ }^{4748}$ or a potential association with patent foramen ovale. ${ }^{49} 50$

\section{Implications for clinical practice}

Our data confirm the association of migraine with white matter hyperintensities. They suggest, however, that this association is not specific to migraine headaches but extends to non-migraine headaches, most likely tension-type headaches. In addition, our data provide evidence that, irrespective of the underlying headache type, the existence of brain lesions among people who have headaches does not result in cognitive impairment. As the association between headache and brain infarcts is limited to the small subgroup of patients who have migraine with aura, our data do not support ordering brain imaging to rule out structural brain lesions for most people with primary headache disorders.

\section{Future research}

Although it does not seem to currently have any clinical relevance, the relation between migraine with aura, white matter hyperintensities, and brain infarcts deserves further investigation. Silent brain infarcts seem to have the same risk factors and mechanisms as clinical stroke but they are many times more common and therefore easier to study. As white matter hyperintensities have been linked with increased risk of stroke, ${ }^{1651}$ a better understanding of the relation between migraine with aura and structural brain lesions could give further insights into whether this association is limited to specific subgroups and whether preventive strategies should be tested. 


\section{WHAT IS ALREADY KNOWN ON THIS TOPIC}

In several case-control and population based studies, migraine has been associated with an increased prevalence of white matter hyperintensities

Migraine with aura has been associated with clinical and subclinical brain infarction

\section{WHAT THIS STUDY ADDS}

Any history of severe headache, not just migraine, is associated with white matter hyperintensities

Associations between migraine and brain infarcts is limited to people who have migraine with aura

Evidence that migraine or other severe headache by itself or in combination with white matter hyperintensities is associated with cognitive impairment is lacking

Contributors: TK conceived and designed the study, analysed the data, and drafted the manuscript. He is guarantor. CT, PM, Y-CZ, and BM acquired the data. All authors interpreted the data, critically revised the draft for important intellectual content, and gave final approval of the version to be published.

Funding: The Epidemiology of Vascular Ageing study was carried out under an agreement between INSERM (Institut National de la Santé et de la Recherche Médicale); Merck, Sharp, and Dohme-Chibret Laboratories (West Point, PA); and EISAI (Paris, France). This study was supported by a chair of excellence grant of the French National Research Agency (ANR, Agence Nationale de la Recherche) to TK. The sponsors were not involved in the design, data collection, analysis, or interpretation of the study nor were they involved in writing the manuscript.

Competing interests: All authors have completed the Unified Competing Interest form at www.icmje.org/coi_disclosure.pdf (available on request from the corresponding author) and declare: that for the specific matter of this research, no support from any organisation for the submitted work; no financial relationships with any organisations that might have an interest in the submitted work in the previous 3 years; no other relationships or activities that could appear to have influenced the submitted work. Other declared interests: TK has received research funds from the US National Institutes of Health, the French National Research Agency (Agence Nationale de la Recherche, ANR), Merck, Migraine Research Foundation, and Parkinson's Disease Foundation; is a consultant to i3 Drug Safety and World Health Information Science Consultants, LLC; and has received honorariums from Genzyme, Merck, and Pfizer for lectures. Y-CZ is funded by the French Chinese Foundation for Science and Applications (FFCSA), the China Scholarship Council, and the Association de Recherche en Neurologie Vasculaire (ARNEVA). HC has received fees from Eisai, Lundbeck, Servier, and Johnson and Johnson for participating on data safety or scientific committees. M-GB has received research support from Sanofi-Synthelabo and Servier. CD has received consulting fees from EISAI. CT has received research funding from the French National Research Agency (ANR) and is receiving fees from Sanofi-Synthelabo for participating in a data safety monitoring board and from Merck, Sharp, and Dohme and Servier for participating in scientific committees.

Ethical approval: This study was approved by the ethics committee of the Hôpital de Kremlin-Bicêtre.

Data sharing: No additional data available.

1 Jensen R, Stovner LI. Epidemiology and comorbidity of headache. Lancet Neurol 2008;7:354-61.

2 Stovner L, Hagen K, Jensen R, Katsarava Z, Lipton R, Scher A, et al. The global burden of headache: a documentation of headache prevalence and disability worldwide. Cephalalgia 2007;27:193-210.

3 Lipton RB, Bigal ME. The epidemiology of migraine. Am J Med 2005;118(suppl 1):3-10S.

4 Tietjen GE, Brandes JL, Digre KB, Baggaley S, Martin V, Recober A, et al. High prevalence of somatic symptoms and depression in women with disabling chronic headache. Neurology 2007;68:134-40

5 Kurth T, Gaziano JM, Cook NR, Logroscino G, Diener HC, Buring JE. Migraine and risk of cardiovascular disease in women. JAMA 2006;296:283-91
6 Bigal ME, Kurth T, Santanello N, Buse D, Golden W, Robbins M, et al Migraine and cardiovascular disease: a population-based study. Neurology 2010;74:628-35.

7 Gudmundsson LS, Scher Al, Aspelund T, Eliasson JH, Johannsson M, Thorgeirsson G, et al. Migraine with aura and risk of cardiovascular and all cause mortality in men and women: prospective cohort study. BMJ 2010;341:3966.

8 Schurks M, Rist PM, Bigal ME, Buring JE, Lipton RB, Kurth T. Migraine and cardiovascular disease: systematic review and meta-analysis. BMJ 2009;339:b3914.

9 Kurth T, Kase CS, Schurks M, Tzourio C, Buring JE. Migraine and risk of haemorrhagic stroke in women: prospective cohort study. $B M$ 2010;341:c3659.

10 Kruit MC, Launer LJ, Ferrari MD, van Buchem MA. Infarcts in the posterior circulation territory in migraine. The population-based MR CAMERA study. Brain 2005;128:2068-77.

11 Scher Al, Gudmundsson LS, Sigurdsson S, Ghambaryan A, Aspelund T, Eiriksdottir G, et al. Migraine headache in middle age and late-life brain infarcts. JAMA 2009;301:2563-70.

12 Vernooij MW, Ikram MA, Tanghe HL, Vincent AJ, Hofman A, Krestin GP, et al. Incidental findings on brain MRI in the general population. N Engl / Med 2007:357:1821-8.

13 Soumare A, Elbaz A, Zhu Y, Maillard P, Crivello F, Tavernier B, et al. White matter lesions volume and motor performances in the elderly. Ann Neurol 2009;65:706-15.

14 Silbert LC, Nelson C, Howieson DB, Moore MM, Kaye JA. Impact of white matter hyperintensity volume progression on rate of cognitive and motor decline. Neurology 2008;71:108-13.

15 Inzitari D, Pracucci G, Poggesi A, Carlucci G, Barkhof F, Chabriat H, et al. Changes in white matter as determinant of global functional decline in older independent outpatients: three year follow-up of LADIS (leukoaraiosis and disability) study cohort. BMJ 2009;339:b2477.

16 Buyck JF, Dufouil C, Mazoyer B, Maillard P, Ducimetiere P, Alperovitch $A$, et al. Cerebral white matter lesions are associated with the risk of stroke but not with other vascular events: the 3-City Dijon Study. Stroke 2009;40:2327-31.

17 Dufouil C, de Kersaint-Gilly A, Besancon V, Levy C, Auffray E, Brunnereau L, et al. Longitudinal study of blood pressure and white matter hyperintensities: the EVA MRI cohort. Neurology 2001;56:921-6.

18 Jongen C, van der Grond J, Kappelle LJ, Biessels GJ, Viergever MA, Pluim JP. Automated measurement of brain and white matter lesion volume in type 2 diabetes mellitus. Diabetologia 2007:50:1509-16.

19 Fazekas F, Koch M, Schmidt R, Offenbacher H, Payer F, Freidl W, et al. The prevalence of cerebral damage varies with migraine type: an MR study. Headache 1992;32:287-91.

20 Cooney BS, Grossman RI, Farber RE, Goin JE, Galetta SL. Frequency of magnetic resonance imaging abnormalities in patients with migraine. Headache 1996;36:616-21.

21 Rocca MA, Colombo B, Pratesi A, Comi G, Filippi M. A magnetization transfer imaging study of the brain in patients with migraine. Neurology 2000;54:507-9.

22 Kruit MC, van Buchem MA, Hofman PA, Bakkers JT, Terwindt GM, Ferrari MD, et al. Migraine as a risk factor for subclinical brain lesions. IAMA 2004;291:427-34.

23 Swartz RH, Kern RZ. Migraine is associated with magnetic resonance imaging white matter abnormalities: a meta-analysis. Arch Neurol 2004;61:1366-8.

24 Intiso D, Di Rienzo F, Rinaldi G, Zarrelli MM, Giannatempo GM, Crociani P, et al. Brain MRI white matter lesions in migraine patients: is there a relationship with antiphospholipid antibodies and coagulation parameters? Eur / Neurol 2006;13:1364-9.

25 Igarashi H, Sakai F, Kan S, Okada J, Tazaki Y. Magnetic resonance imaging of the brain in patients with migraine. Cephalalgia 1991;11:69-74.

26 De Benedittis G, Lorenzetti A, Sina C, Bernasconi V. Magnetic resonance imaging in migraine and tension-type headache. Headache 1995; 35:264-8.

27 Dufouil C, Ducimetiere P, Alperovitch A. Sex differences in the association between alcohol consumption and cognitive performance. EVA Study Group. Epidemiology of vascular aging. Am J Epidemiol 1997:146:405-12.

28 Dufouil C, Alperovitch A, Ducros V, Tzourio C. Homocysteine, white matter hyperintensities, and cognition in healthy elderly people. Ann Neurol 2003:53:214-21.

29 Tzourio C, Gagniere B, El Amrani M, Bousser MG, Alperovitch A. Lay versus expert interviewers for the diagnosis of migraine in a large sample of elderly people. / Neurol Neurosurg Psychiatry 2003;74:238-41.

30 Tzourio C, El Amrani M, Poirier O, Nicaud V, Bousser MG, Alperovitch A. Association between migraine and endothelin type A receptor (ETA-231 A/G) gene polymorphism. Neurology 2001;56:1273-7. 
31 Tzourio C, Tehindrazanarivelo A, Iglesias S, Alperovitch A, Chedru F, d'Anglejan-Chatillon J, et al. Case-control study of migraine and risk of ischaemic stroke in young women. BMJ 1995;310:830-3.

32 Olesen J, Steiner TJ. The international classification of headache disorders. 2nd ed (ICDH-II). J Neurol Neurosurg Psychiatry 2004;75:808-11.

33 Stovner LJ, Andree C. Prevalence of headache in Europe: a review for the Eurolight project. J Headache Pain 2010;11:289-99.

34 Maillard P, Delcroix N, Crivello F, Dufouil C, Gicquel S, Joliot M, et al. An automated procedure for the assessment of white matter hyperintensities by multispectral (T1, T2, PD) MRI and an evaluation of its between-centre reproducibility based on two large community databases. Neuroradiology 2008;50:31-42.

35 Folstein MF, Folstein SE, McHugh PR. "Mini-mental state." A practical method for grading the cognitive state of patients for the clinician. J Psychiatr Res 1975;12:189-98.

36 Willett W, Stampfer MJ. Total energy intake: implications for epidemiologic analyses. Am J Epidemiol 1986;124:17-27.

37 Launer LJ, Terwindt GM, Ferrari MD. The prevalence and characteristics of migraine in a population-based cohort: the GEM study. Neurology 1999;53:537-42.

38 Gruber HJ, Bernecker C, Pailer S, Lechner A, Horejsi R, Moller R, et al. Lipid profile in normal weight migraineurs-evidence for cardiovascular risk. Eur J Neurol 2010;17:419-25.

39 Rozen TD, Swanson JW, Stang PE, McDonnell SK, Rocca WA. Increasing incidence of medically recognized migraine headache in a United States population. Neurology 1999;53:1468-73.

40 Baars MA, van Boxtel MP, Jolles J. Migraine does not affect cognitive decline: results from the Maastricht aging study. Headache 2010;50:176-84.
41 Kruit MC, Launer LJ, Ferrari MD, van Buchem MA. Brain stem and cerebellar hyperintense lesions in migraine. Stroke 2006;37:1109-12.

42 Martins KM, Bordini CA, Bigal ME, Speciali JG. Migraine in the elderly: a comparison with migraine in young adults. Headache 2006;46:312-6.

43 Paemeleire K. Brain lesions and cerebral functional impairment in migraine patients. J Neurol Sci 2009;283:134-6.

44 Chabriat H, Joutel A, Dichgans M, Tournier-Lasserve E, Bousser M-G. Cadasil. Lancet Neurol 2009;8:643-53.

45 Vanmolkot FH, Van Bortel LM, de Hoon JN. Altered arterial function in migraine of recent onset. Neurology 2007;68:1563-70.

46 Napoli R, Guardasole V, Zarra E, Matarazzo M, D’Anna C, Sacca F, et al. Vascular smooth muscle cell dysfunction in patients with migraine. Neurology 2009;72:2111-4.

47 Schurks M, Zee RY, Buring JE, Kurth T. Interrelationships among the MTHFR 677 C $>$ T polymorphism, migraine, and cardiovascular disease. Neurology 2008;71:505-13.

48 Scher Al, Terwindt GM, Picavet HS, Verschuren WM, Ferrari MD, Launer LJ. Cardiovascular risk factors and migraine: the GEM population-based study. Neurology 2005;64:614-20.

49 Schwedt TJ, Demaerschalk BM, Dodick DW. Patent foramen ovale and migraine: a quantitative systematic review. Cephalalgia 2008;28:531-40.

50 Nozari A, Dilekoz E, Sukhotinsky I, Stein T, Eikermann-Haerter K, Liu C, et al. Microemboli may link spreading depression, migraine aura, and patent foramen ovale. Ann Neurol 2010;67:221-9.

51 Debette S, Markus HS. The clinical importance of white matter hyperintensities on brain magnetic resonance imaging: systematic review and meta-analysis. BMJ 2010;341:c3666.

Accepted: 12 October 2010 